\title{
Barriers in Adoption of Health Information Technology in Developing Societies
}

\author{
Fozia Anwar \\ Health Informatics Unit \\ COMSATS Institute of Information Technology \\ Islamabad, Pakistan
}

\author{
Azra Shamim \\ Computer Science Department \\ COMSATS Institute of Information Technology \\ Islamabad, Pakistan
}

\begin{abstract}
This paper develops the conceptual framework of barriers faced by the decision makers and management personnel of health sector. The main theme of this paper is to give a clear understanding about the adaption barriers of health technology faced by developing societies. The information about barriers would be useful for policy makers to decide about the particular technology. So that they can fulfill the defined mission of their organizations. Developing a conceptual framework is the first step in building organizational capacity. Information technology in health sector is spreading globally. Use of health information technology is offering evidence-based practice to endorse health and human prosperity. Globalization of health information system is inevitable for establishment and promotion of healthcare sector in developing societies. Present health systems in developing societies are inadequate to meet the needs of the population. Health sector of developing societies is facing a lot of barriers in establishment and promotion of health information system. These barriers include lack of infrastructure, cost, technical sophistications, lack of skilled human resources and lack of e- readiness of medical professionals. In this paper authors conducted a survey of hospitals in Pakistan to identify and categorized adaption barriers in health information technology. Existing health system should be transformed by using HIT to improve health status of population by eliminating barriers identified in this paper.
\end{abstract}

Keywords-component; Health Technolog; Health Information System; Barrier in e- Health.

\section{INTRODUCTION}

Health information technology (HIT) consists of set of technologies with a great diversion for transmitting and managing health care data for the use of all stakeholders. Stakeholders of health information include payer, providers and all other groups having interest in health and health care system [1].

HIT means the use of computer in the form of physician digital assistance, electronic health records, computerized physician order entry system by doctors, patients, hospitals, laboratories, x-ray facilities and all other stake holders. Health information technology is very important part of constantly changing environment of health care system. With the use of HIT, health related information can be communicated well and can be used in evidence based decision making process [2]. Benefits of HIT include reduced paper work in hospital environment [3] which results in reducing medical errors, minimizing the repetition of medical tests which affects in lowering health care cost [4]. Evidence-based practices play a key role in efficient health information system quality, outcome and efficiency of health. Health care system can be improved by having timely and accurate information for evidence based decisions at all levels [5]. Proactive uses of information technology in health sector empowers consumers of health services as they can easily access health information as well as decision tool and by the employment of HIT, health professionals can collaborate more easily when distance is a major factor [6]. In past HIT applications were used for administrative activities and financial activities rather assisting and delivering health care [7].

The rest of the paper is organized into different sections. Section 2 gives an overview of research methodology. Section 3 presents literature review. Barriers faced by under developed countries in establishment of HIT are discussed in Section 4. Results are presented in section 5 Section 6 discusses suggestions. Section 7 concludes the research work.

\section{RESEARCH METHODOLOGY}

This paper presents a cross sectional quantitative survey. The focus of authors is to identify potential barriers of information technological interventions in health sector. Sample size is 9 hospitals of Rawalpindi and Islamabad cities; 4 hospitals are from government and 5 are from public sector. Convenience sample technique was used for the study. Sample size will be taken without taking it in consideration that whether they are private or government, teaching or non teaching, profitable or non profitable hospitals. Inclusion criteria is that any hospital having at least two departments computerized or having their departmental information system regardless of their integration within the department or within the hospitals. Data was analyzed by using SPSS. Only percentages and frequencies are used for analysis.

\section{LITERATURE REVIEW}

\section{A. Health Information Technology (HIT)}

Health information system is spreading worldwide and thus promoting health and prosperity for humans. Simplest definition of hospital information system is "Computer application in hospital" [8]. HIS is an N- tier application suit built for a single location or multi location environment [9]. Important features of an effective and functional HIS should 
include easy, friendly and ready to use, well integrated, customization property and possible tracking and alert facility. Least but not last automation back up is necessary so that no data loss should occur [10].

\section{B. Health Technology}

The term health technology covers a range of methods used to promote health services, prevent diseases and treat them appropriately. With the use of health technology short-term care (rehabilitation) and long term care which include drugs, devices and procedures can be improved. There are few examples of health information technology used in different health setups which include the computerization of medical records in hospitals and clinics, use of Internet for document delivery, information exchange and communication, development of e-cards for patient identification, development of electronic scheduling system to give appointments, hospital labs and hospital admission examination and computerized protocol for diagnosis and giving treatment support. HIT system provides improved decision-making and appropriate use of diagnostic laboratory tests and therapeutic agents.

\section{BARRIERS FACED BY UNDERDEVELOPED COUNTRIES IN ESTABLISHMENT AND PROMOTION OF HIT}

Presently health information system infrastructure is deficient in resources to meet the demands and needs of increasing population in developing countries. Health care systems of developing countries have major barriers like poverty and lack of technological sophistication. The basic difficulties or barriers in using information technologies include poor or inadequate infrastructure, insufficient access to the hardware and inadequate or poor resources allocation. By eliminating these barriers population health status can be improved in developing countries. [10]

The authors have identified following barriers in establishment and promotion of HIT in under developed countries. These barriers are divided into six groups i.e. ICT Infrastructure, cost and time, national policies toward HIT, social and cultural, educational, organizational, and ethical barriers.

\section{A. Barriers Related To Infrastructure}

Most of underdeveloped countries do not have required technological infrastructure to establish national health information system [11] hence cannot promote HIT in private and public hospitals. Reshaping infrastructure of existing health system is very crucial. The following is description of infrastructural barriers:

- $\quad$ Poor or Inadequate Infrastructure

Most developing countries do not have adequate required infrastructure such as computer hardware, software, wired and wireless communication channels, Internet, and skilled professional human resource. The availability and operation of these components of ICT Infrastructure are necessary for establishment and promotion of HIT in under developed countries. Strong infrastructure is required for the strong health information system to improve existing health system by planning and introducing new health care interventions which results in achieving better health goal [12],[13],[14]. There are poor or inadequate resources allocation for implementation and use of the health technology in the developing countries.

- $\quad$ Provision of Computer Hardware and Software

HIT requires specialized software and hardware to improve public health by making evidence based decisions. Often these software and hardware tools are costly and require sufficient training for proper operation.

\section{- $\quad$ Poor Internet Availability}

Poor internet availability is a vital infrastructure barrier. Health care specialists have poor access to real time information and the available information is not according to the local situation. This available information cannot be used for evidence based decisions. Without having a proper local area network and internet facility inter-organizational and intraorganizational communication is not possible. This is a backbone for any information system [14], [15].

- $\quad$ Lack of Professional Human Resource Workforce nd Lack of Trainings to Produce this Workforce

A computerized information system requires skilled personnel for its effective operation. Training is one of the aspects for use of any new technology. Deficiency of skilled workforce can be overcome by providing appropriate training in the required area. A proper training module in constructing architecture of a reliable database should be available. If it is not implemented then outcomes or results gained by such type of databases gives unauthentic results which can neither be used for decision making process nor for evidence based practice. Training requires cost as well as time.

\section{B. Cost and Time Barriers}

Major problem in organizing workshops and trainings for establishment and implementation of HIT in under developed countries is financial and time constraint [14], [16], [17], [18]. Transformation of any system is a difficult task and cannot complete in short time period. Barriers like lack of skilled workforce, infrastructure, and cost along with other effects like initial decrease of productivity due to adjustment with new technological environment and system itself impose, strong limits to the introduction and adaption of new health technologies [14], [18]. It requires years and years for transformation process to complete.

\section{National Policies towards HIT}

Efficient, effective and secure national policy can address the local health needs according to the changing environment is needed. These policies can be devised by policy makers and practitioners to assess and implement research evidences [14], [16]. Enforcing the legislation is difficult in developing countries and acceptance by the community for the transformation of any system is harder [14], [20]. Total amount of Rs. 663 billion has been allocated in PSDP (Public Sector Development Program) 2010-11 for various ongoing and new schemes Out of this only Rs.16944.5 million gas been allocated for development of Health Division with $2.1 \%$ population average annual growth which is abysmally low [21]. 


\section{Social and Cultural Barriers}

Digital divide and e-readiness are major social and cultural barriers in establishment and use of health information system. These barriers include lack of stakeholder's interest, less motivation, anxiety to adapt and use new technology. Health care personnel are difficult to convince for use of new health technologies. As they are more comfortable with their conventional approach and routine practice so it is complicated to transform health information system from paper based to digital format [14], [22].

\section{E. Educational Barriers}

Professional education in health informatics is badly ignored and missing in curriculum of medical institutes for undergraduates. Although module of education related to IT use in research is included in postgraduate curriculum but it is the need of the hour to include this area in medical professional education at graduate level. Transformation of our existing paper based health system into computerized information system is not possible without providing the basic IT knowledge to health professionals.

\section{F. Organizational Barriers}

Organizations and people play a very critical role in implementing and transformation of an information system. First of all there are no documented studies available regarding level and use, benefits, cost, risk analysis and other aspects of health technology in health sector of underdeveloped countries and if they are available for the developing countries they are not well communicated. Secondly, people at higher positions and posts, whose needs of reporting are adequately being catered by the existing system, do not favor HIT as they think that the employment of new technology is wastage of both the money and time. Hospitals must address the apprehension of physicians because if by using HIT their professional responsibilities become difficult they will never support its use [23].

\section{RESULTS AND DISCUSSIONS}

Barriers are classified into different 7 categories. These 7 categories were further explored in context with:

- Important issues decisive in adapting new technology

- Factors not recommending new technology

- Factors affecting adaption of technology despite recommendation of the management

- Factors influencing making decisions about adaption of technology

In figure 1 initial cost barrier is shown. This is a barrier for both private and government sector but private hospitals gave more emphasis on initial cost barrier.

Figure 2 despite ongoing costs analysis and concludes that both private and government hospitals consider it as a barrier but again private hospitals give more importance to this barrier as they are strongly agree that cost is an issue.

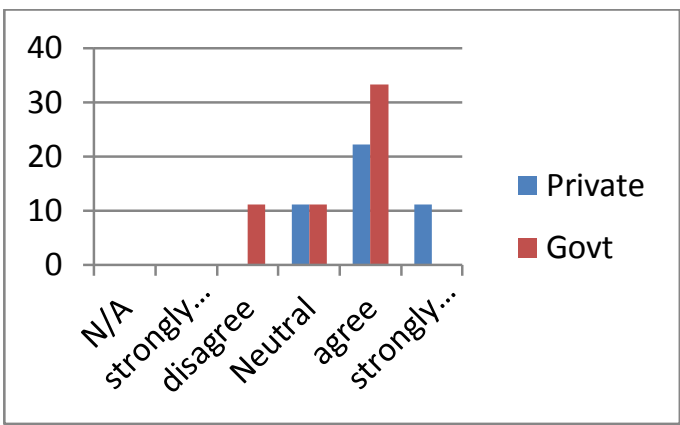

Figure 1. Initial Cost Barrier

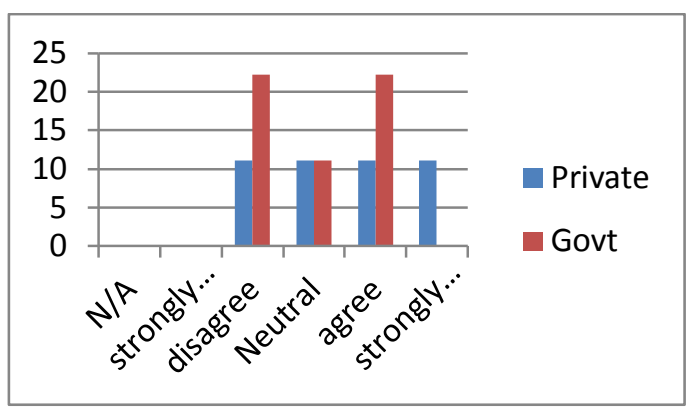

Figure 2. Maintenance Cost

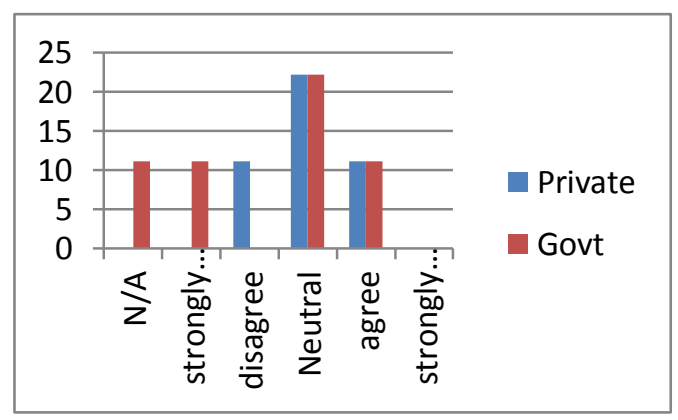

Figure 3. Unproven Returns on Investments

In figure 3 profiles of unproven returns on investment is shown. Both public and private sector agree at the same level. Documented proofs about the success and investment return are not available and even if they are available they are not well communicated to the decision making authorities and stakeholders. Total cost for the establishment of health information system includes acquisition, infrastructure, implementation, maintenance and training cost as shown in the following equation:

$\operatorname{CosT}_{\mathrm{T}}=\operatorname{COST}_{\mathrm{A}}+\operatorname{COST}_{\mathrm{IF}}+\operatorname{CoST}_{\mathrm{IM}_{\mathrm{M}}}+\operatorname{COST}_{\mathrm{M}}+\operatorname{COST}_{\mathrm{T}}$

Where

$\mathrm{COST}_{\mathrm{T}}$ is the total cost

$\operatorname{COST}_{\mathrm{A}}$ is acquisition cost

$\operatorname{COST}_{\mathrm{IF}}$ is infrastructural cost

$\operatorname{COST}_{\mathrm{IM}}$ is implementation cost

$\operatorname{COST}_{\mathrm{M}}$ is maintenance cost

$\mathrm{COST}_{\mathrm{T}}$ is training cost

Furthermore acquisition cost includes cost of hardware and software as shown in the following equation: 
$\operatorname{COST}_{\mathrm{A}=} \operatorname{COST}_{\mathrm{H}}+\mathrm{COST}_{\mathrm{S}}$

$\operatorname{COST}_{\mathrm{H}}$ is hardware

$\mathrm{COST}_{\mathrm{S}}$ is software

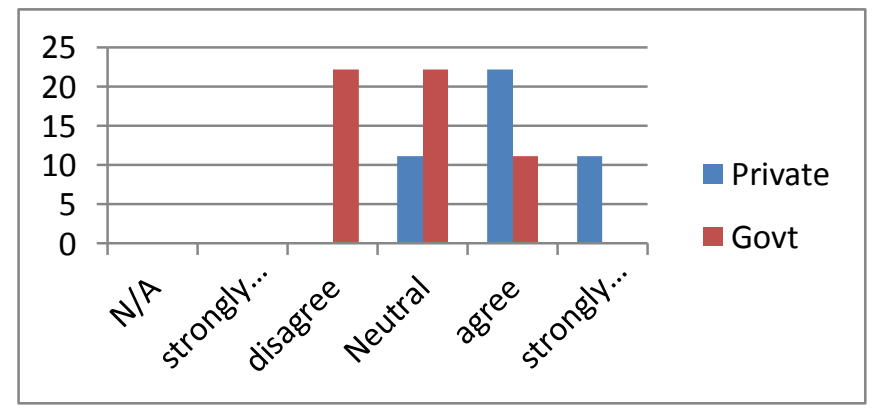

Figure 4. Acceptance by Clinical Staff

In figure 4 behavioral barriers in the form of acceptance by the clinical staff is shown. Private sector seems to be more sensitive to this barrier at high level as compared to the government sector. The reason might be that in government sector all clinical and administrative staff must have to follow the commands as they have no other options while in private sector they can switch to another setup easily.

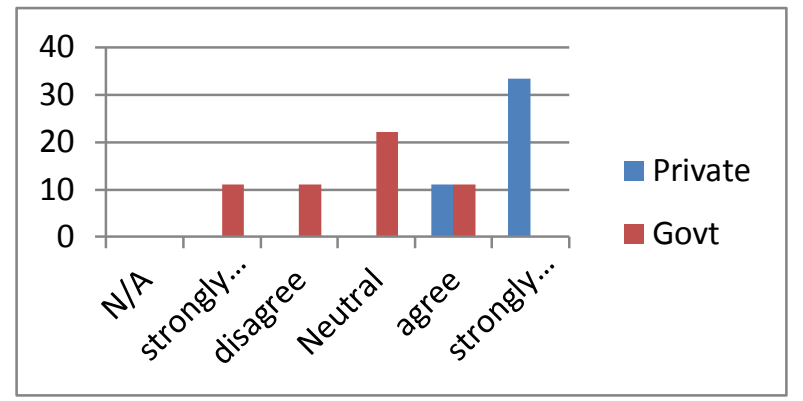

Figure 5. Unavailability of Well Trained IT Staff

Figure 5 shows the unavailability of well-trained IT staff as a barrier in adaption of health technology.

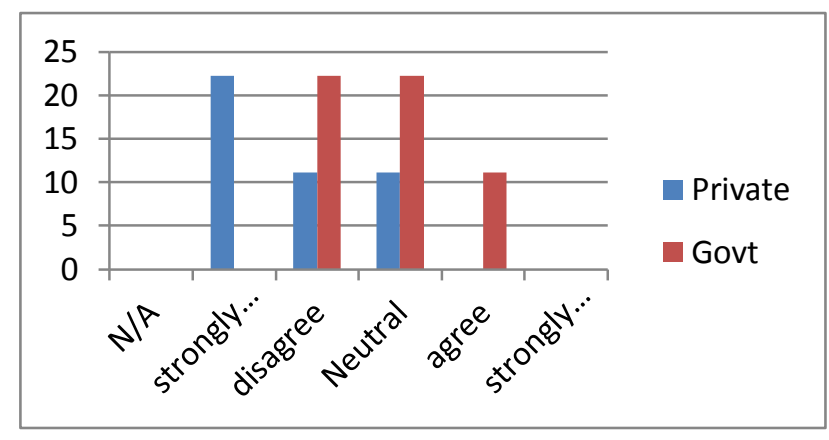

Figure 6. Difficult to Use

In figure 6 barriers regarding the difficulty to use new technology is shown. Only government sector agrees that this is a barrier for adaption of new health technology. Reason behind is that government employees have security about their jobs while personnel in private sector have to update their skills and knowledge accordingly. Interoperability of existing and new system is shown in figure 7 .

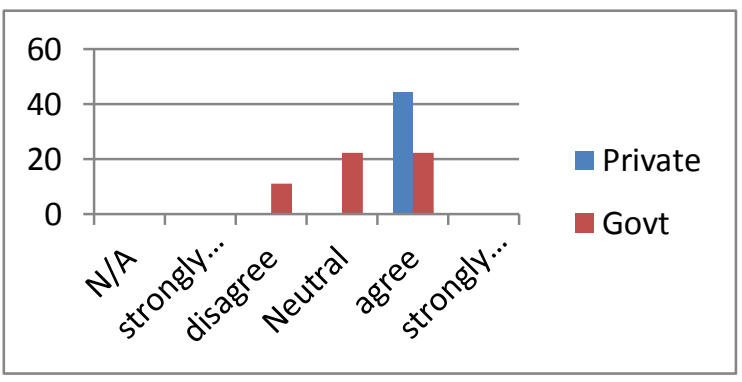

Figure 7. Interoperability with Current System

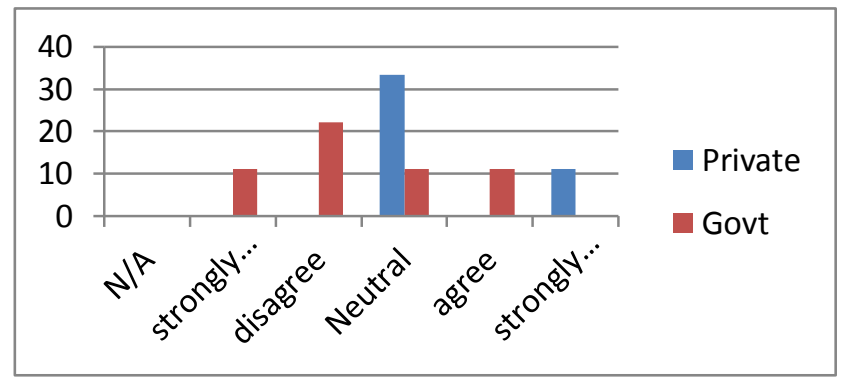

Figure 8. Not Enough Time for Training

As hospitals have a great workload of outpatient and inpatient so sparing time for training to adapt new health technology is a major concern as shown in figure 8 .

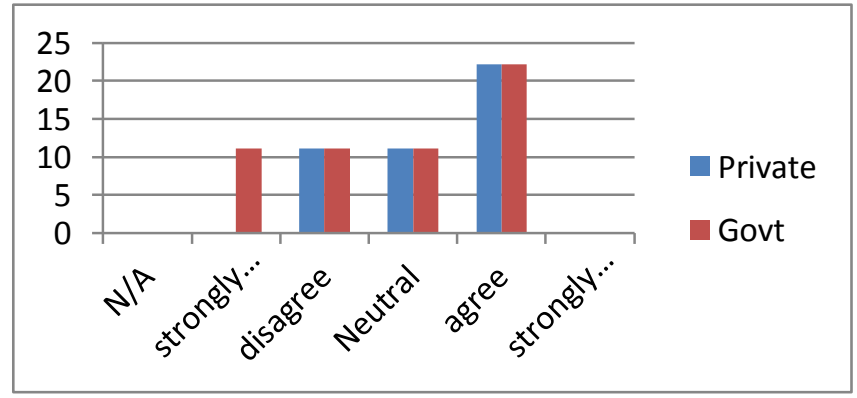

Figure 9. Difficulty in Changing Work Flow Pattern

Figure 9 shows change in current workflow pattern as a barrier. This is a very important aspect for both public and private sector in adaption of any new health technology. Any small change in workflow due to adaption of new health technology affects more on the clinical and administrative functions of the hospital. Change in current workflow pattern of any hospital cannot be made in small time period.

In figure 10 helping factors in making decision about adaption of technology are categorized. Emphasis by ministries or government policies, knowledge translation and feedback are the important factors which help in implementing new technologies in hospitals. Next important helpful factor is stage or phase adaption then factors physician demand and transparent funding formula come. Physician will be demand new health technology in their working environment only when knowledge translation will be improved and they will aware of the benefits of new health technology. And emphasis by ministry or authorities is an important helpful factor considered. 


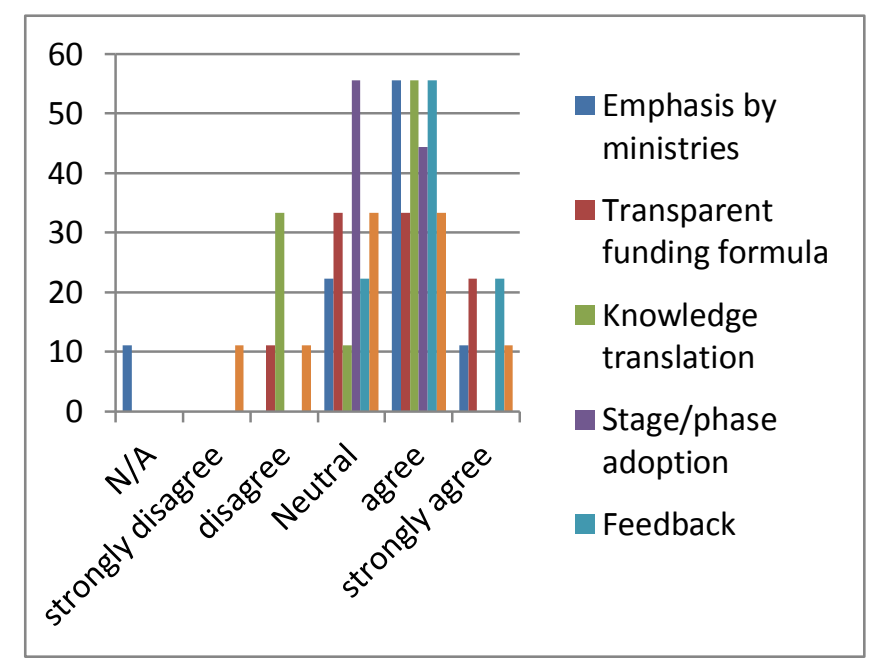

Figure 10. Factors Influencing Making Decision about Adaption of Technology

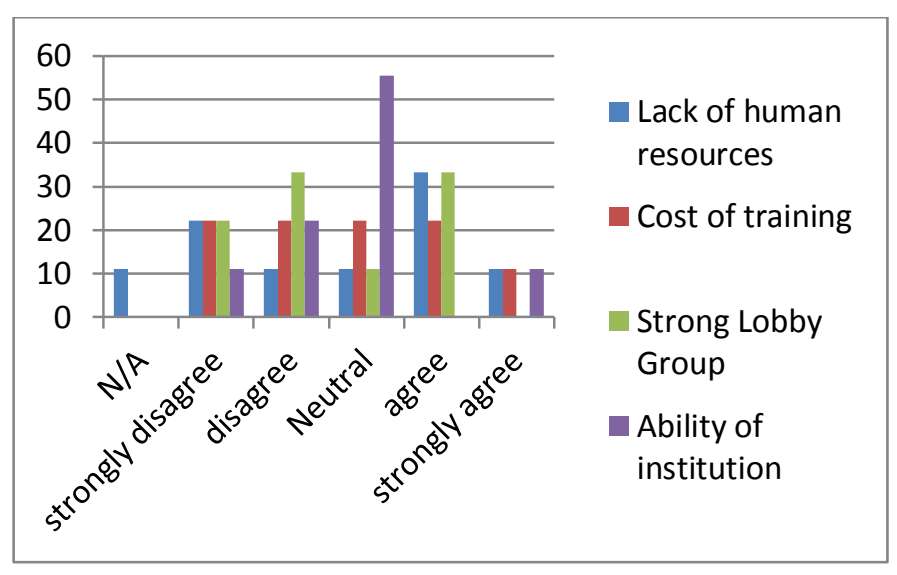

Figure 11. Factors Affecting Adaption of Technology despite Recommendation of the Managment

In figure 11 barriers are categorized according to their effect in adaption of technology despite recommendation of the management. Strong lobby group of the health personnel due to many authentic reasons is one of the main factors. The other factor is lack of qualified and trained human resource to operate and maintain new health technology. Cost of training is also a barrier for management to adapt new health technology.

\section{SugGeStions}

Fixed and implicit percentage of the total budget of hospital should be allocated for the health informatics or health / IT department. Good collaboration is strongly required between health informatics personnel and professional group for a better understanding. So a group of people should be trained in both the fields of informatics and health. Thus they can act as a bridge between these two professions.

The government, ministry of health or other stakeholders might impose the important measures for adaption of health technology to promote HIT. New flexible methods for implementations should be adapted. Phase adaption is recommended. Initially the existing system and new technology should be run side by side. Hundred percent changes in the system track sometimes lead to failure.

\section{CONCLUSION}

Adaption barriers of new health technology are hot issue in developing societies. Developed countries have adapted new health technologies in their health sector to a great extent. Developing countries are still struggling for it and facing a lot of barriers like lack of infrastructure, cost, time and benefit analysis, lack of skilled workforce, national policies and motivation of health related personnel. It is high time to recognize that evidence-based informatics is very helpful in putting science into the field or practice. Enough professional skills related to HIT are lacking. HIS cell or health technology projects are lacking in budget. The time period, which is required for well implementation of the specific health technology, is quite long.

As Informatics is a constantly changing field and technology is advancing day by day, so when you implement one technology the new version or latest technology comes. System up-gradation along with this change is unavoidable. Complexity in maintaining, integrating and interoperability with the existing system make the use of health technology very hard and difficult. These barriers are main hurdle in adaption of health technologies and by addressing these barriers adaption process can be successful.

\section{REFERENCES}

[1] David Blumenthal and John Glaser, Information Technology Comes to Medicine" , New England Journal of Medicine Vol. 356, 24th , June 2007

[2] Innovators and Visionaries: Strategies for Creating a Person-centered Health System. FACCT: Foundation for Accountability; September 2003.

[3] Health Information Technology, Can HIT Lower Costs and Improve Quality? 2005 RAND Corporation. RAND Health research reported http://www.rand.org/pubs/research_briefs/RB9136/index1.html

[4] Using Health Information Technology to Manage Your Information Computers Can Help You and Your Doctor Manage Your Health Care, Michael Bihari, MD, former About.com Guide Updated April 06, 2010

[5] http://www.thefreedictionary.com/health+information+system, Accessed Date: June 2010

[6] Innovation of health technology, Report by centre of AHIP centre of policy and research, Effective new solution for Americans health insurance plans

[7] Audet AM, Doty MM, Peugh J, Shamasdin J, Zapert K, Schoenbaum S, Information technologies: when will they make it into physicians' black bags? MedGenMed. 2004; 6:2. [PMID: 15775829](13)

[8] health information support, regional office for the eastern Mediterranean, WHO, Cairo Egypt, May, 2001

[9] www.hospitalinformationsystem.com visited on 16th April, 2011

[10] Laurence J. Krieg, Introduction to hospital information system module M30c, Washtenair community college, 26 march1999.

[11] www.who.int/topics/millennium...goals/.../ICT_for_Accountability.pdf

[12] Azubuike M. C. J.E. Ehiri, Health information systems in developing countries: benefits, problems, and prospects, The Journal of the Royal Society for the Promotion of Health, Vol. 119, No. 3, pp 180-184 (1999), DOI: 10.1177/146642409911900309, ( 1999 Royal Society for the Promotion of Health,

[13] Lansang MA, Dennis R, Building capacity in health research in the developing world, Bull World Health Organ. 2004 Oct;82(10):764-70, Review, PMID: 15643798 [PubMed - indexed for MEDLINE] 
[14] Mugdha R Oak, A review on barriers to implementing health informatics in developing countries, Journal of Health Informatics in developing countries, vol 1, No. 1, 2007

[15] Sluijs MB, Veeken H, Overbeke AJ., Deficient information in developing countries: Internet alone is no solution, Ned Tijdschr Geneeskd. 2006 Jun 17; 150(24):1351-4, Dutch, PMID: 16808368,

[16] Chinnock Paul, Global review on access to health information in developing countries, Discussion Paper 1. The role of systematic reviews, Cochrane Collaboration, http://www.hiurope.co.uk/files/2004/9962.htm

[17] Garner Paul et. al., Getting research findings into practice Implementing research findings in developing countries, BMJ 1998, pp 531-535, 22nd August, 1998 ,

[18] McDonald Michael D., Health Information Infrastructure in Developing Countries, Global Health Initiatives, Inc., http://www.greenstar.org/GHI/Developing\%20Countries.htm
[19] Martínez A, et al. Analysis of information and communication needs in rural primary health care in developing countries, IEEE Trans Inf Technol Biomed. 2005

[20] Tan Tessa, Torres Edejer. Information in practice Disseminating health information in developing countries: the role of the Internet, BMJ 2000; 321, pp 797-800, 30th September 2000

[21] Pakistan budget 2010-2011 http://www.onepakistan.com/finance/budget/index.php Accessed on 12th April 2011.

[22] Tan Tessa, Torres Edejer. Information in practice Disseminating health information in developing countries: the role of the Internet, BMJ 2000; 321:797-800, 30 September 2000

[23] Reider J. Cedars-Sinai Medical Center suspends CPOE, January 2003. (Accessed Date May 24, 2007, Available at http://www.docnotes.net/000866.html.) 